\title{
Traffic restriction policies in an urban avenue: A methodological overview for a trade- off analysis of traffic and emission impacts using microsimulation
}

Paulo Fernandes, Jorge M. Bandeira, Tânia Fontes, Sergio Ramos Pereira, Bastian J. Schroeder, Nagui M. Rouphail, and Margarida C. Coelho

\section{QUERY SHEET}

This page lists questions we have about your paper. The numbers displayed at left can be found in the text of the paper for reference. In addition, please review your paper as a whole for correctness.

Q1. Au: "re-placing"-correct? Will this be understood by your readers?

Q2. Au: Is it possible to add spaces around the multiplication symbols in Table 6?

Q3. Au: Adding "of scenarios" okay here?

Q4. Au: Is it possible to add spaces around multiplication symbols in Table 7?

Q5. Au: "Dr." Rouphail okay?

Q6. Au: Please Provide Publisher Or Url For Acap (2012).

Q7. Au: Please Provide Publisher Location For Everitt \& Hothorn (2006).

Q8. Au: Please Provide Updated Publication Information For Fontes Et Al. (In Press).

Q9. Au: Please Clarify Publisher And Publisher Location For Pearson, Pearson, \& Hartley (1966).

\section{TABLE OF CONTENTS LISTING}

The table of contents for the journal will list your paper exactly as it appears below:

Traffic restriction policies in an urban avenue: A methodological overview for a trade-off analysis of traffic and emission impacts using microsimulation

Paulo Fernandes, Jorge M. Bandeira, Tânia Fontes, Sergio Ramos Pereira, Bastian J. Schroeder, Nagui M. Rouphail, and Margarida C. Coelho 


\title{
Traffic restriction policies in an urban avenue: A methodological overview for a trade- off analysis of traffic and emission impacts using microsimulation
}

\author{
Paulo Fernandes ${ }^{a}$, Jorge M. Bandeira ${ }^{a}$, Tânia Fontes ${ }^{a}$, Sergio Ramos Pereira ${ }^{a}$, Bastian J. Schroeder ${ }^{b}$, Nagui M. Rouphail ${ }^{b}$, \\ and Margarida C. Coelho ${ }^{a}$
}

5 a Department of Mechanical Engineering/Centre for Mechanical Technology and Automation, University of Aveiro, Aveiro, Portugal; ${ }^{\mathrm{b}}$ Institute for Transportation Research and Education, North Carolina State University, Raleigh, NC, USA

\section{ABSTRACT}

Urban traffic emissions have been increasing in recent years. To reverse that trend, restrictive traffic measures can be implemented to complement national policies. We have proposed a methodology to assess the impact of three restrictive traffic measures in an urban arterial by using a microsimulation model of traffic and emissions integrated platform. The analysis is extended to some alternative roads and to the overall network area. Traffic restriction measures provided average reductions of $45 \%, 47 \%, 35 \%$, and $47 \%$ for $\mathrm{CO}_{2}, \mathrm{CO}, \mathrm{NO}_{x}$, and $\mathrm{HC}$, respectively, due to traffic being diverted to other roads. Nevertheless, increases of $91 \%, 99 \%, 55 \%$, and $121 \%$ in $\mathrm{CO}_{2}, \mathrm{CO}, \mathrm{NO}_{\mathrm{x}}$, and $\mathrm{HC}$, respectively, can be expected on alternative roads.

\section{ARTICLE HISTORY}

Received 10 April 2013

Accepted 16 January 2014

Revised 15 January 2014

\section{KEYWORDS}

Emissions; integrated platform; microscopic simulation; traffic restriction measures

\section{Introduction and objectives}

In Europe, emissions of greenhouse gases (GHGs) from the transportation sector increased by $19 \%$ between 1990 and 2011 and account for about $20 \%$ of total emissions (EEA, 2013).

20 Some tools have been developed to quantify the impacts of current urban patterns of transportation on emission impacts and air quality (Bandeira, Coelho, Sá, Tavares, \& Borrego, 2011; Barros, Fontes, Silva, \& Manso, 2013; Coelho, Farias, \& Rouphail, 2009). In the last decade, several measures were devel25 oped to improve air quality in cities. These measures can either be from the vehicle side or the road side. Focusing on road-side measures, optimization tools for traffic signal timing are used to reduce fuel consumption and vehicular emissions as well as traffic delays and stops (Stevanovic, Stevanovic, Zhang, \& Bat-

30 terman, 2009; Zhang, Chen, Zhang, Song, \& Yu, 2009). In addition to these, traffic restriction measures represent effective yet unpopular tools to both reduce vehicular congestion and improve air quality within the city centers. Nonetheless, a measurable improvement in air quality is needed to demonstrate

35 the effectiveness of those measures (Castro \& Delos Reyes, 2010; Invernizzi et al., 2011).

The use of microsimulation models has recently become more commonplace in the study of transportation problems regarding environmental implications of policy measures. Spe-

40 cifically, these models allow exporting the vehicle position and vehicle dynamics (acceleration/deceleration and speed) secondby-second, which provides accurate emission estimation. Note that their simulation outputs as speed and acceleration/deceleration can be employed in instantaneous emissions models. impacts of different traffic management strategies applied to the road network traffic, such as, route diversion, lanes management, variable speed limits, or traffic signal coordination (Aziz \& Ukkusuri, 2011).

The methodology usually followed in previous works was to integrate a traffic model with an emission model. Table 1 lists the most relevant studies on the effects of traffic restriction measures on vehicular emissions and traffic performance using a simulation approach. Moreover, it indicates the spatial and temporal extents, and also the environmental and performance goals proposed in each work. These studies can be divided into two main groups. In the first group (Chen \& Yu, 2007; Int Panis et al., 2011; Nesamani, Chu, \& Recker, 2010; Qu, Rillet, Zhang, \& Zietsman, 2003; Torné, Rosas, \& Soriguera, 2011), only one traffic restriction measure is assessed; and in the second group (Lee et al., 2012; Mahmod, Van Arem, Pueboobpaphan, \& Igamberdiev, 2010), comparisons of several traffic restriction measures for the same location are conducted.

Many studies have proven to be inconclusive about the environmental benefits of speed limit reductions ( $\mathrm{Qu}$ et al., 2003, Torné et al., 2011) and bus-only lane implementation (Chen \& $\mathrm{Yu}, 2007)$. Madireddy et al. (2011) concluded that the reduction of speed limits from $50 \mathrm{~km} / \mathrm{h}$ to $30 \mathrm{~km} / \mathrm{h}$ in residential areas provided a $25 \%$ reduction of carbon monoxide (CO) and nitrogen oxide $\left(\mathrm{NO}_{\mathrm{X}}\right)$ emissions.

Mahmod et al. (2010) suggested that reducing traffic demand and heavy duty vehicles led to a decrease of $\mathrm{CO}, \mathrm{NO}_{\mathrm{x}}$, and $\mathrm{PM}_{10}$ emissions by more than $20 \%$. Lee et al. (2012) found that the fleet replacement of Drayage trucks by lower-emission trucks on an urban freight corridor yielded a significant

CONTACT Paulo Fernandes paulo.fernandes@ua.pt. E University of Aveiro, Centre for Mechanical Technology and Automation, Campus Universitário de Santiago, 3810-193 Aveiro, Portugal.

() 2015 Taylor \& Francis Group, LLC 


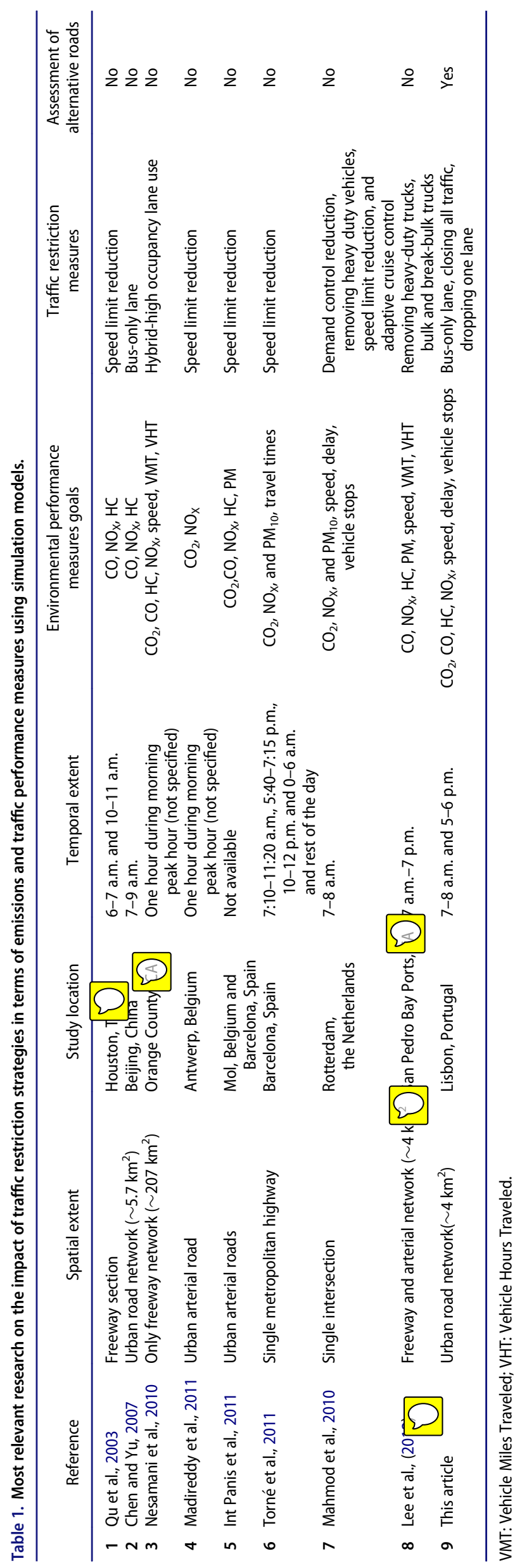


reduction in $\mathrm{NO}_{\mathrm{X}}$ and particulate matter (PM) emissions in $48 \%$ and 55\%, respectively, between 2012 and 2005. Nesamani et al. (2010) showed that hybrid-high occupancy lanes were less effective with regard to flow-mixed lanes when hybrids' per80

centage exceeded $19 \%$.

From the above-mentioned references some observations can be made. First, the majority of researchers used different traffic simulation tools to analyze the effect of traffic restriction measures in limited study areas (Int Panis et al. 2011; Madir-

85 eddy et al., 2011; Mahmod et al., 2010; Qu et al., 2003). Second, some studies with a significant spatial extent analysis (Chen \& Yu, 2007; Lee et al., 2012; Nesamani et al., 2010) were focused on one time analysis period. Third, the effects of traffic restriction measures in other individual road networks were not taken

into account.

Thus, a more extensive analysis that combines both emissions and traffic performance assessment is needed. The analysis should include different network areas within the case study at different periods of the day in order to reflect reality and

95 improve the knowledge to develop further traffic restriction strategies. In this study (see Table 1), we seek to contribute to the literature by providing a more accurate assessment of traffic restriction strategies in urban areas. As such, we developed a methodology to evaluate multiple traffic restrictions using a 100 microsimulation approach.

This paper intends to focus on the following research questions:

- How can different traffic restriction measures affect emissions and traffic performance on multiple roads in the study area?

- How do vehicular emissions vary during morning and evening peak hours for different traffic restriction measures?

Section 2 describes the methodology developed in this study.

110 Information regarding simulation steps, data sources used in its development, and an application in a real-world case study are provided in detail. Next, analysis results are presented and discussed in section 3, followed by the main conclusions in Section 4.

\section{2. Material and methods}

The main goal of the proposed methodology is to develop a microscopic simulation platform of traffic and emissions. This platform allows direct evaluation of the impact of traffic restriction measures on the atmospheric environment in urban areas.

120 A summary of the modeling framework is depicted in Figure 1. The models (see section 2.1), as well as data collection (see section 2.2) and the methodology for calibration and validation (see section 2.3) are described briefly herein. Finally, a realworld case study (see section 2.4) with traffic restriction meas-

125 ures is presented (see section 2.5).

\subsection{Platform of microscopic traffic and emission modeling}

To evaluate traffic restriction measures at the urban level, we defined a microscopic simulation platform of traffic and emissions. This approach attempts to represent traffic and emissions

130 on a second-by-second basis.

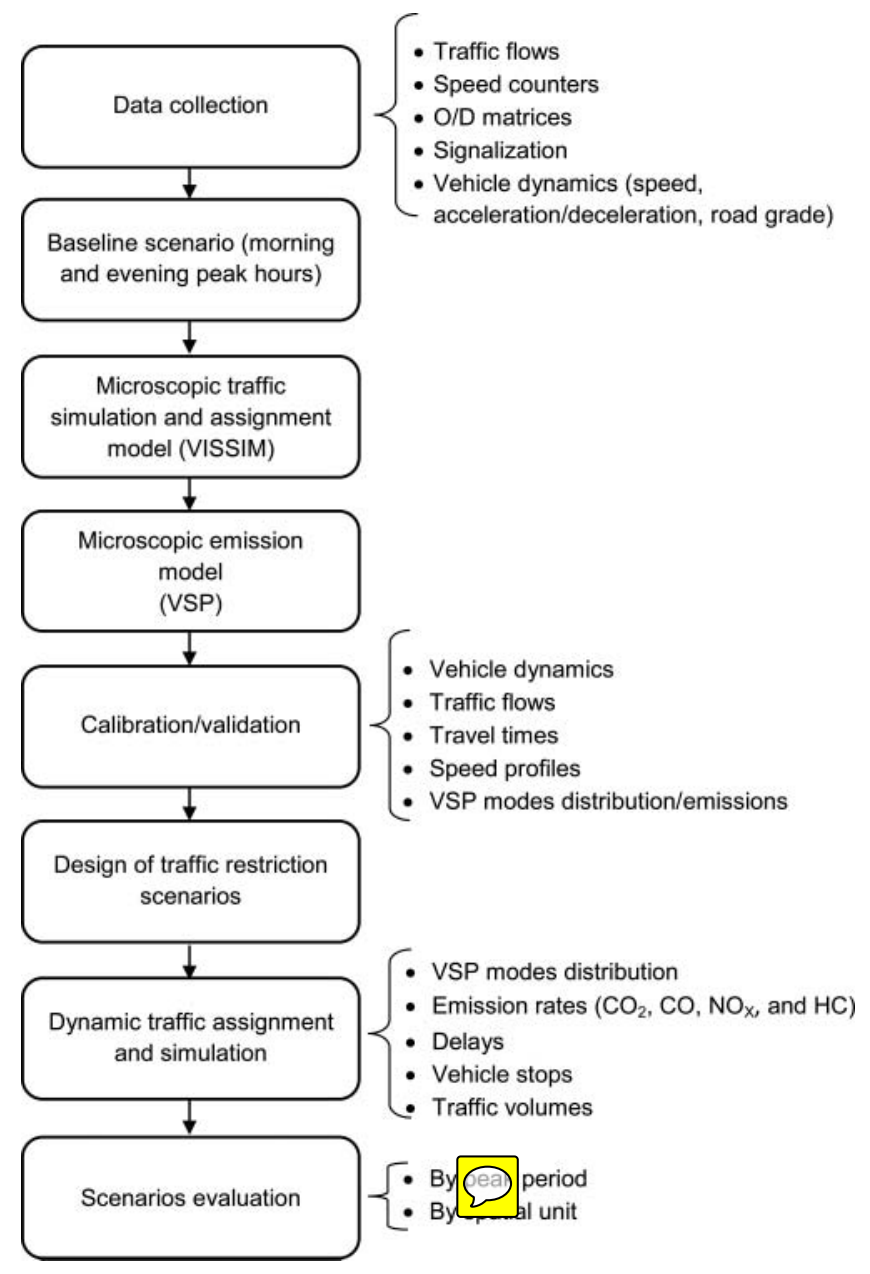

Figure 1. Methodological simulation framework.

A microscopic traffic model describes the behavior of individual drivers as they react to their perceived surroundings. It also offers detailed vehicle operation and instantaneous speed and acceleration of vehicles required by the microscopic emission models in order to evaluate the environmental impact of transportation policies such as traffic restriction measures. We used the VISSIM 5.30 microscopic traffic model to simulate traffic conditions (PTV, 2011). VISSIM was selected because of the possibility to define and use different road-user behavior parameters and submodels (car-following, gap-acceptance, lane change) for different vehicle types and traffic controls modeling (PTV, 2011). A good deal of literature has documented the effective use of VISSIM in analyzing some traffic restriction and management strate $i$ in real-world case studies (Chen \& $\mathrm{Yu}, 2007$; Fontes et al., 2 Mahmod et al., 2010).

The emission calculation is made by using the "Vehicle Specific Power" (VSP) methodology. This model is based on vehicle speed, acceleration/deceleration, and road grade and has proven to be very useful in estimating instantaneous emissions for gasoline and diesel vehicles (Coelho, Frey, Rouphail, Zhai, \& Pelkmans, 2009; Frey, Zhang, \& Rouphail, 2008) as well as transit buses (Zhai, Frey, \& Rouphail, 2008). Several motivations have supported the use of VSP methodology in this research: (a) VSP can be applied for both U.S. and European car fleets because it includes a wide range of engine displacement values; (b) VSP methodology was shown to produce 
accurate trip fuel consumption estimates for diesel transit buses (Frey, Rouphail, Zhai, Farias, \& Gonçalves, 2007); and (c) recent research (Kolak, Feyzioglu, Birbil, Noyan, \& Yalcindag,

160 2013) concluded that the VSP-based emission model not only has a better estimation of vehicle emissions than a speed-based emission model but also is capable of reflecting the emission changes under different operating modes.

The VSP values are categorized in 14 modes and an emis-

165 sion factor for each mode is used to estimate carbon dioxide $\left(\mathrm{CO}_{2}\right), \mathrm{CO}, \mathrm{NO}_{\mathrm{X}}$, and hydrocarbons $(\mathrm{HC})$ emissions from Light Duty Diesel Vehicles (LDDV $<1.8$ L) and Light Duty Gasoline Vehicles (LDGV $<3.5 \mathrm{~L})$. Equation 1 provides the VSP calculation for Light Duty Vehicles (LDV) (U.S. EPA, 2002):

$$
\begin{aligned}
& V S P=v \times[1.1 \times a+9.81 \times \sin (\arctan (\text { grade }))+0.132] \\
& +0.000302 \times v^{3}
\end{aligned}
$$

171 where:

$v=$ Instantaneous speed $(\mathrm{m} / \mathrm{s})$;

$a=$ Instantaneous acceleration or deceleration $\left(\mathrm{m} / \mathrm{s}^{2}\right)$;

grade $=$ Road grade (decimal fraction).
These terms represent the engine power required in terms of kinetic energy, road grade, friction, and aerodynamic drag (Frey et al., 2008). VSP values are usually grouped in combinations of $1 \mathrm{~kW} /$ ton from -50 to +50 . Then, these values are categorized in modes so that each mode generates an average emission rate. Concerning transit buses, VSP is estimated using typical coefficient values and expressed by Equation (2) (Zhai et al., 2008):

$$
V S P=v \times[a+9.81 \times \sin (\text { grade })+0.092]+0.00021 \times v^{3}
$$

where:

$v=$ Instantaneous speed $(\mathrm{m} / \mathrm{s})$;

$a=$ Instantaneous acceleration or deceleration $\left(\mathrm{m} / \mathrm{s}^{2}\right)$;

grade $=$ Road grade (decimal fraction) .

In this case, VSP combinations are grouped in eight modes that correspond to values ranging from -30 to $30 \mathrm{~kW} /$ ton (Zhai et al., 2008).

Table 2 presents the average modal emission rates for LDGV, LDDV, and transit buses based on VSP bins. After the VSP value is calculated, the VSP mode is determined by the

175

for VSP modes for Light Duty Diesel Vehicles (LDDV), Light Duty Gasoline Vehicles (LDGV), and transit unses.

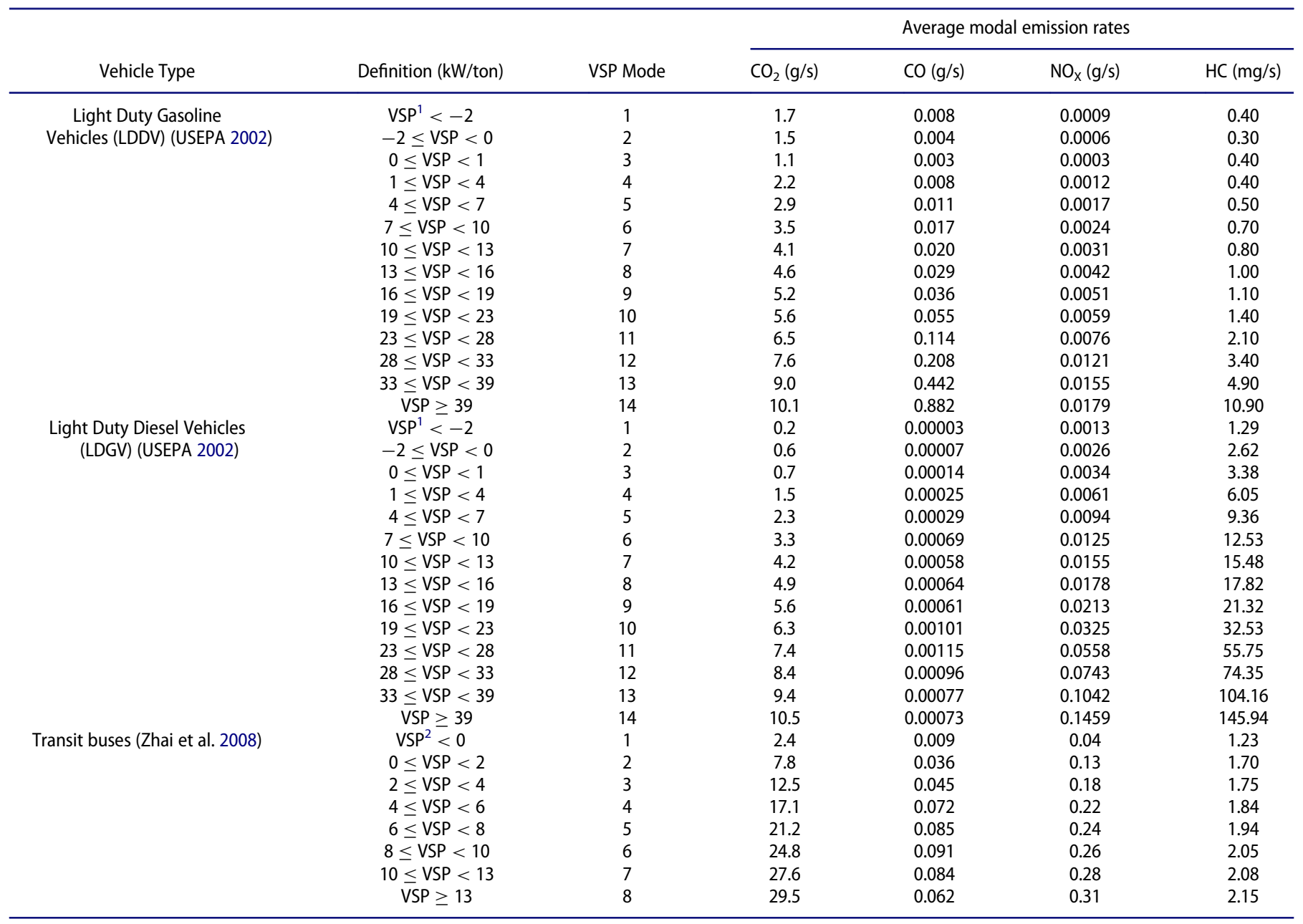

'As computed by Equation (1)

${ }^{2}$ As computed by Equation (2) 
VSP range. The corresponding modal emission rates for $\mathrm{CO}_{2}$, $\mathrm{CO}, \mathrm{NO}_{\mathrm{X}}$, and $\mathrm{HC}$ are then obtained.

\subsection{Data collection}

Several inputs are required to the integrate platform of microsimulation. For this process, the following data collection must be provided:

1) Traffic counts by vehicle class;

2) Speed counts;

3) Time-dependent matrices;

4) Cycle length and green times for traffic lights;

5) Vehicle dynamics (speed, acceleration/deceleration, and road grade).

This data collectio $P$ as performed on several roads and took into account several factors: network and route types, traffic demand, driver scheduling, and selected vehicles classes. Note that all data collection deman s s collected hourly, with the exception of vehicle dynar

\subsection{Model calibration and validation}

Model calibration and validation are very crucial processes in traffic simulation analyses. Before calibrating, we must define which performance measures to use as an index of comparison

215 between simulation results and collected data. In this study, we selected travel times and speed as the main calibration data for urban case studies because these measures reflect the driving behavior parameters and the level of service (Dowling, Skabadonis, \& Alexiadis, 2004).

220 In this paper, we present a calibration and validation methodology that can be performed in five steps. The first three steps are related to the calibration of the traffic model, while the following steps are focused on validation of the simulated data.

225 First we calibrate both the desired speed and acceleration distributions. then the driver behavior parameters of the traffic model us order to assess their effect on trave hes and speed. These can be divided into car-following parameters (average standstill distance, additive and multiple part of safety

230 distance), lane-change parameters, and simulation resolution. The calibration strategy recommended by Dowling et al. (2004) (2a) followed. This included the following: first calibrate capacity parameters, then route choice parameters, and finally the overall model performance. In each step, all parameters that

235 affect the simulation on a global basis first and then those that have an impact on a local basis (i.e., link-specific parameters) should be adjusted.

In the third step, a preliminary number of runs are selected using traffic volumes, trav $\mathrm{t}$ hes, average speed, and accelera-

240 tion measures, separately. Tne methodology suggested by Hale (1997) is followed.

To validate the results of the traffic simulation model we carried out a comparison between traffic counts, trav nes, speeds, and acceleration with observed data for a preliminary

245 number of runs selected previously. The Geoffrey E. Havers (GEH) statistic test (Dowling et al., 2004) and the Root Mean Square Error (RMSE) (FHWA Travel Mode Improvement
Program, 2010) are used to compare means and overall "goodness of fit," respectively.

The fifth step is focused on a comparison between observed 250 and estimated VSP mode distributions and respective $\mathrm{CO}_{2}$, $\mathrm{CO}, \mathrm{NO}_{\mathrm{X}}$, and $\mathrm{HC}$ emissions. Because the number of data sets (number of seconds of the route) is roughly higher than 30 (Everitt \& Hothorn, 2006) the two-sample Kolmogorov-Smirnov test (K-S test) for a 95\% confidence level is appropriate to assess if the probability distributions of two samples are different.

\subsection{Selected case study}

To evaluate the efficacy of an integrated platform on traffic restriction measures assessment, we selected an urban arterial in Lisbon (Portugal). The case study network is comprised of a wide central road, two service roads and four signalized intersections. Due to its central location, Liberdade Avenue (LA) has a high traffic demand that can reach 1,600 vehicles/hour on its central roads during evening peak hours. Thus, this road network is an interesting case for studying traffic restriction measures to evaluate their effects on emission and road traffic performance parameters. Figure 2 shows the map of city study area with the LA and alternative roads 1 (AR1) and 2 (AR2) identified. These roads allowing traffic in both directions are the only ones that provide similar trips to LA. Overall speed limit in the study area is $50 \mathrm{~km} / \mathrm{h}$.

In this domain, the data required for the integrated platform of traffic and emissions presented in section 2.3 were collected. Network-wide traffic demands (see Figure 2), and traffic signal and average speed counters were obtained from the Traffic and Road Safety Department of Lisbon Municipality. These local $\mathrm{O} / \mathrm{D}$ matrices (see Figure 2) have resulted from surveys that have been carried out in different areas of Lisbon's central area during the morning and evening peak periods. The above O/D matrices included both LDV and heavy duty vehicles. Concerning traffic counts data, they included the following vehicles types: Light Duty Vehicles, Heavy Duty Vehicles, and transit buses. Because Heavy Duty Vehicles represented less than 1\% of traffic composition, we excluded them from this evaluation. After that, we adjusted global O/D demands (between centroids) to match traffic flows data in $60 \mathrm{~min}$ intervals on the road loop detectors with available data. We performed this procedure on both morning peak and evening peak periods. For intersections without traffic data, we assumed turning flow fractions similar to those of neighboring locations. Regarding urban traffic buses, their schedules, headways, and bus stop locations were calibrated using the real values of the Lisbon Bus Company. Data were collected in four routes across LA in order to cover all trips that can be performed on the central and service roads. For each route, we performed or than 30 runs.

The emission model was used to estimate $\mathrm{CO}_{2}, \mathrm{CO}, \mathrm{NO}_{\mathrm{X}}$, and $\mathrm{HC}$ emissions for LDV and transit buses. In order to reflect the actual Portuguese fleet as closely as possible, the considered emissions rates are based on 57.5\% LDGV and 42.5\% LDDV with engine size smaller than 3.5 L (ACAP, 2012). We aned that the effect of road grade was not relevant (grade $\Omega$ To support this, we compared $\mathrm{CO}_{2}, \mathrm{CO}, \mathrm{NO}_{\mathrm{X}}$, and $\mathrm{HC}$ emissions, 


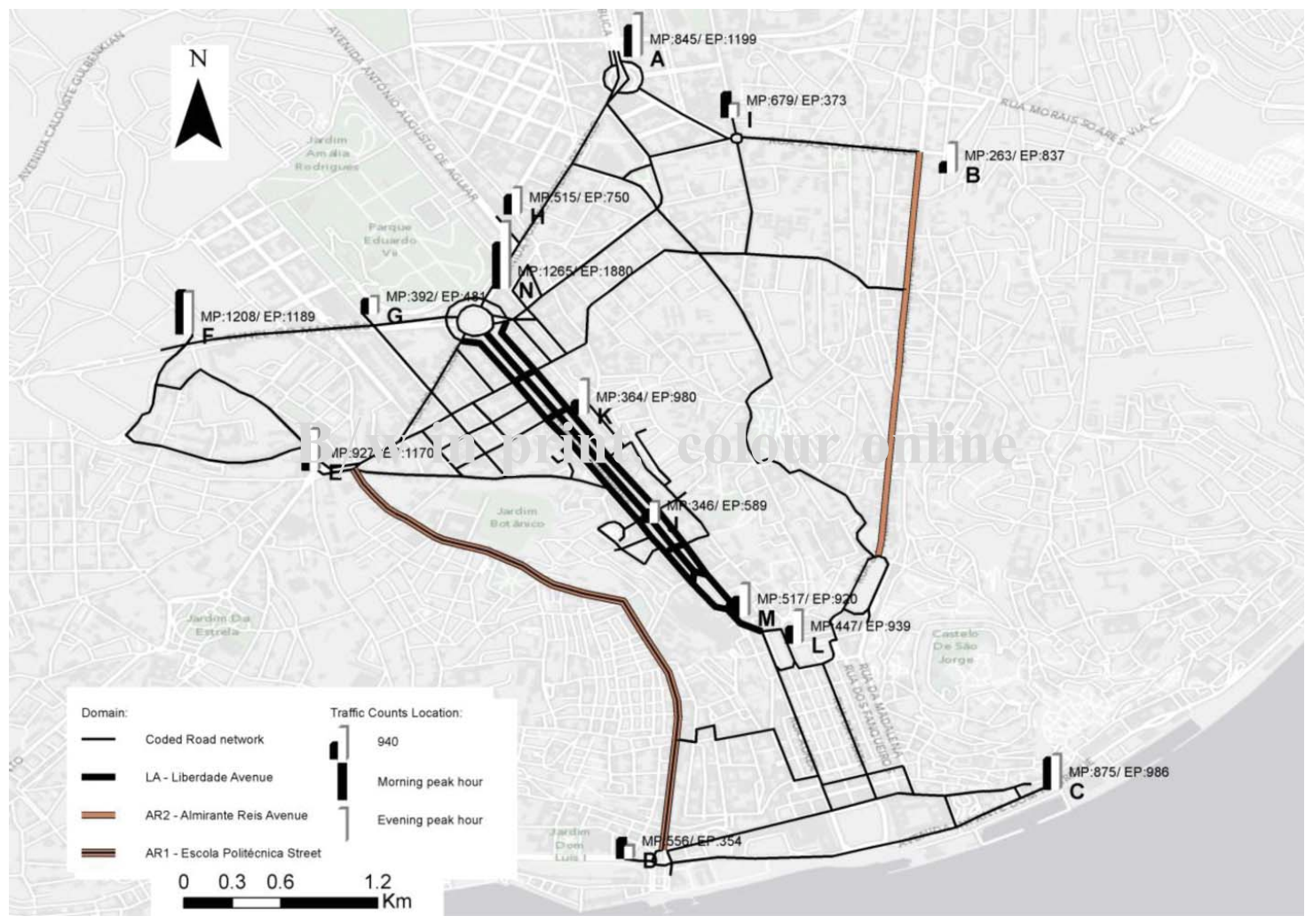

Figure 2. Study domain.

Calibration and validation were done for the baseline scenario. This scenario corresponds to the reference situation on the LA corridor in which traffic flow is assigned to routes by using Dynamic Traffic Assignment (DTA) (PTV, 2011). In order to

325 assess emissions and traffic performance of several traffic restrictions, three traffic scenarios to be implemented on the LA corridor are evaluated (Figure 3):

- Baseline scenario: This corresponds to the actual situation of LA in which traffic flow is assigned to routes on the basis of a traditional user equilibrium model (Figure 3.a);

- Scenario 1: Removal of left lane on the central road of LA (southeast to northwest direction) with 750 meters of length. Additionally, service road capacity is reduced to one circulating lane with 3.5 meters of width (Figure 3.b);

- Scenario 2: Implementation of a bus-only lane in the central road of LA with 800 meters of length (Figure 3.c);

- Scenario 3: Similar to scenario 2, but the central road of LA is closed to traffic (Figure 3.d).

In these scenarios, we also assumed that traffic is diverted to the alternative roads by applying DTA in the VISSIM model, considering the travel time as the only factor impacting routes choice (PTV, 2011). This was done due to the fact that no information about driver's route choice factors in the study domain could be found. Because bus stops were in the same location for both scenarios 1 and 2, we considered that transit buses had the same path from origin to destination as in the baseline scenario. There was an exception in scenario 3 in which the bus stops located on the central road were re-placing at the lateral roads.

The emissions and traffic performance of each traffic restriction scenario are evaluated in terms of: (a) LA; (b) AR1 and AR2; and (c) overall network (ON). Traffic flows, number of stops, and estimated acceleration and deceleration profiles are derived from the vehicle dyn $\mathrm{m}$ s data (second-by-second), while delays are obtained from he node evaluation (PTV, 355 2011).

\section{Results and discussion}

In this section we present and discuss the main results obtained from traffic and emissions models calibration and validation (see section 3.1). After that, environmental and performance 

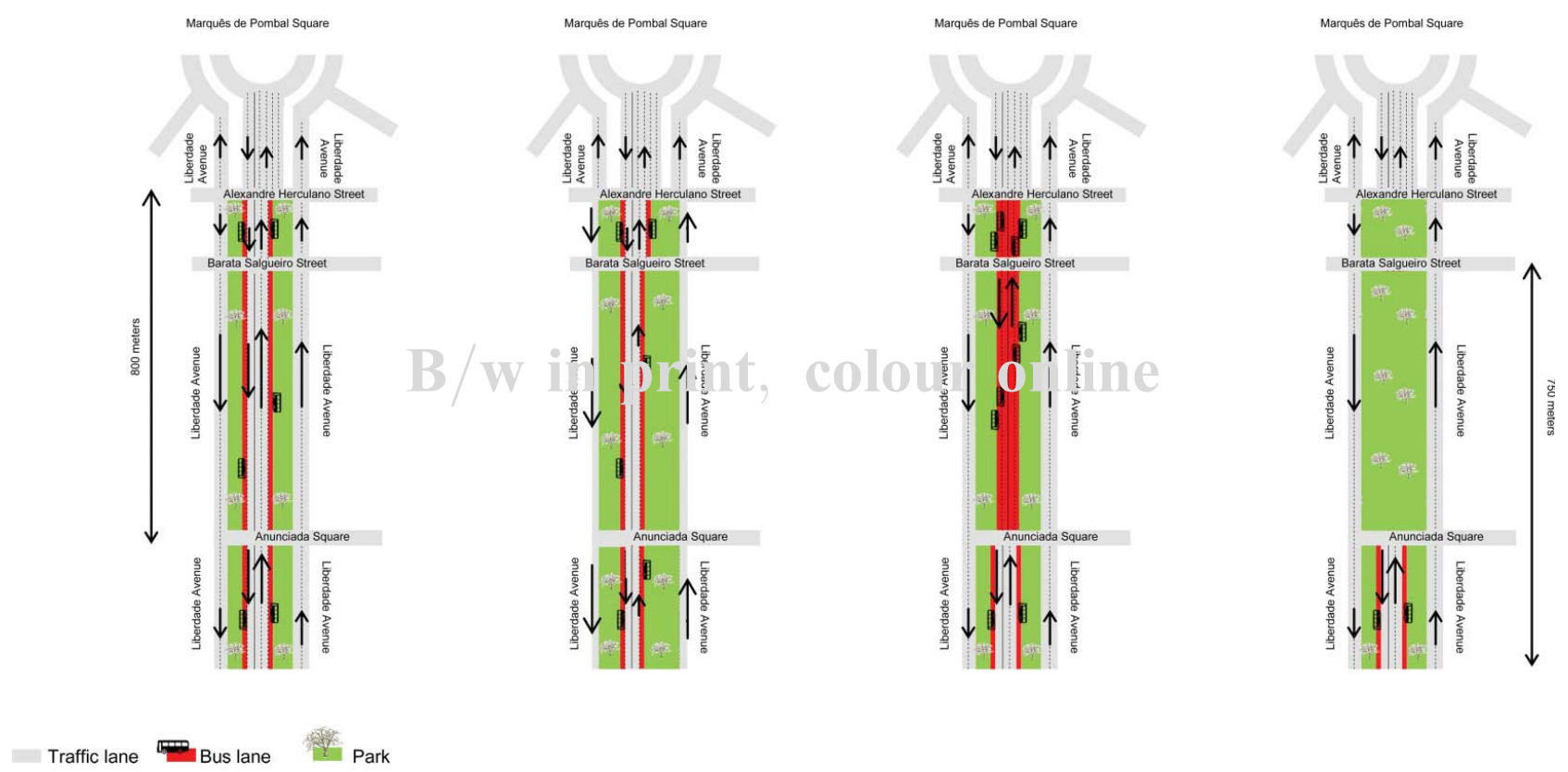

Figure 3. Schematic of traffic restriction scenarios: (a) baseline scenario; (b) scenario 1; (b) scenario 2; (d) scenario 3.

Table 3. Observed and simulated trave and mean speed (VISSIM default parameters) during the morning peak hour.

\begin{tabular}{|c|c|c|c|c|c|}
\hline Parameter & (200) & Sample size $\left(\mathrm{N}_{\mathrm{MIN}}\right)$ & Observed $(95 \% \mathrm{Cl})$ & Simulated $(95 \% \mathrm{Cl})$ & GEH statistic \\
\hline \multirow{2}{*}{ Travel time (seconds) } & 2 & $14(4)$ & $191.2(11.0)$ & 171.4 (6.6) & 1.5 \\
\hline & 3 & $10(6)$ & $410.7(7.8)$ & $380.2(18.3)$ & 1.5 \\
\hline \multirow[t]{3}{*}{ Speed $(\mathrm{km} / \mathrm{h})$} & 1 & $10(3)$ & $18.1(0.8)$ & $20.1(0.7)$ & 2.0 \\
\hline & 2 & $14(4)$ & $25.8(0.1)$ & $28.5(0.6)$ & 2.3 \\
\hline & 3 & $10(6)$ & $15.0(0.5)$ & $17.2(1.0)$ & 1.5 \\
\hline
\end{tabular}

(iD) pacts from traffic restriction measures during the morning

Table 4. Observed and simulated traffic flows (vph) for morning and evening peak hours.

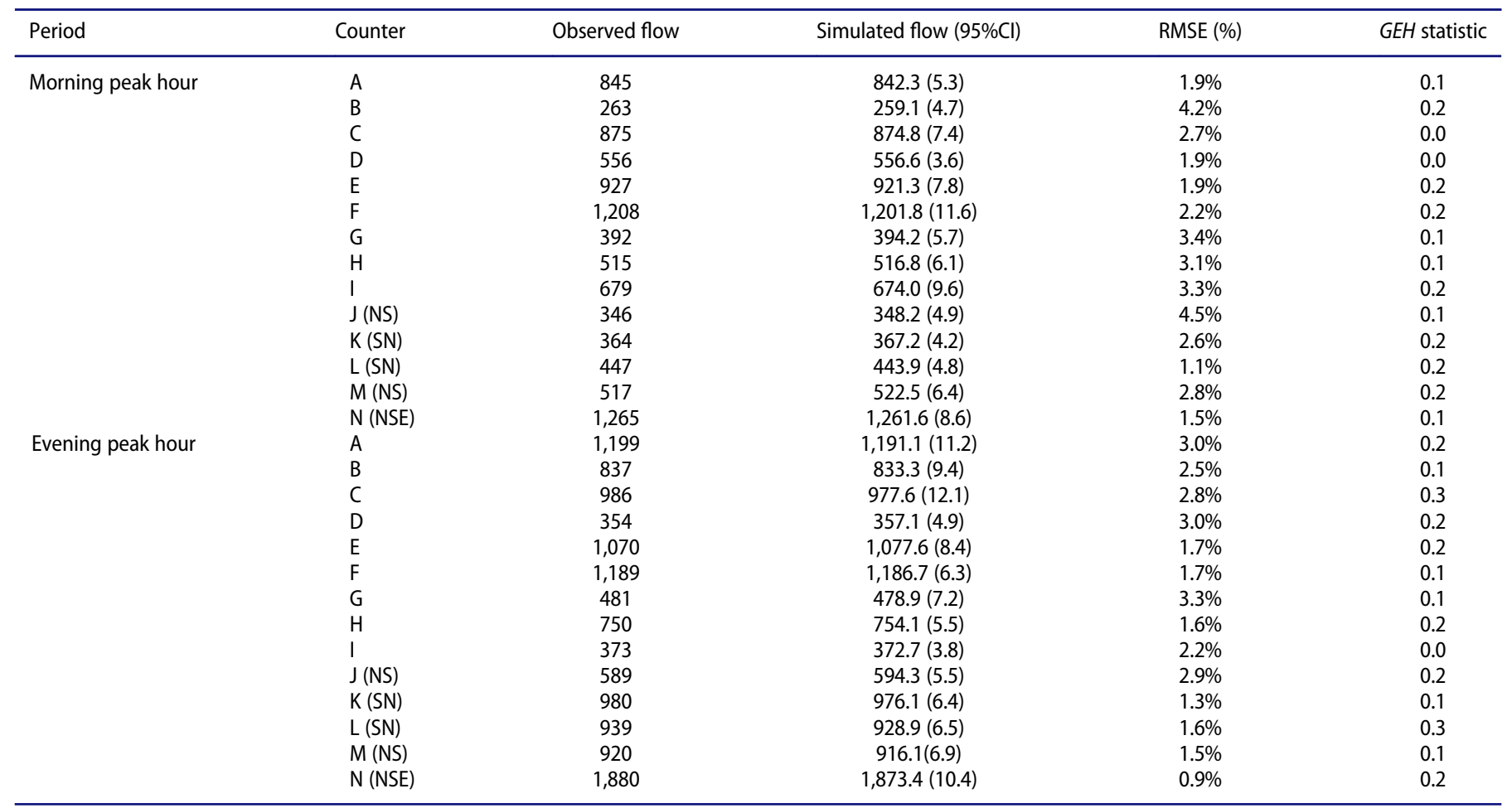

Notes. N—north direction; S—south direction; SN—northwest to southeast direction; NS—southeast to northwest direction; NSE—northeast to southwest direction. 
Table 5. Observed and simulated travel time and speed (calibrated parameters) during the morning peak hour.

\begin{tabular}{|c|c|c|c|c|c|}
\hline Parameter & Route & Sample size $\left(\mathrm{N}_{\mathrm{MIN}}\right)$ & Observed $(95 \% \mathrm{Cl})$ & Simulated $(95 \% \mathrm{Cl})$ & GEH statistic \\
\hline \multirow[t]{4}{*}{ Travel time (seconds) } & 1 & $10(6)$ & $311.6(15.9)$ & $309.6(5.0)$ & 0.1 \\
\hline & 2 & $16(14)$ & $191.2(11.0)$ & $188.7(3.7)$ & 0.2 \\
\hline & 3 & $8(4)$ & $410.7(7.8)$ & $400.3(5.3)$ & 0.5 \\
\hline & 4 & $8(2)$ & $288.3(12.4)$ & $286.8(3.8)$ & 0.1 \\
\hline \multirow[t]{4}{*}{ Speed (km/h) } & 1 & $10(6)$ & $18.1(0.8)$ & $19.0(0.7)$ & 0.2 \\
\hline & 2 & $16(14)$ & $25.8(0.1)$ & $26.4(0.7)$ & 0.1 \\
\hline & 3 & $8(4)$ & $15.0(0.5)$ & $15.7(0.4)$ & 0.2 \\
\hline & 4 & $8(2)$ & $19.8(0.8)$ & $20.3(0.5)$ & 0.1 \\
\hline
\end{tabular}

peak, evening peak, and both time periods in the selected case study are presented and analyzed (see section 3.2).

\subsection{Model calibration and validation}

365 As suspected, the first runs using VISSIM default parameters proved that there are differences between observed and simulation values of performance measures. The results from VISSIM for both travel times and a ere speed are presented in Table 3, using madel default parannerers and a number of floating car

370 runs ( Q N) higher than recommended by Dowling et al. (2004). It was cl 2 hat the simulated values intervals did not include observed values intervals (Dowling et al., 2004). Similar results recorded from the comparison between observed and simulated speed counters data on several arterials of the

375 study domain. VISSIM also presents several limitations on acceleration/deceleration rates modeling, namely: (a) acceleration/ deceleration profiles are not modeled as speed profiles (a range of values) (PTV, 2011); (b) predicted acceleration is overestimated in relation to observed data (Fellendorf \& Vortisch, 2010); and (c) when vehicles attain their desired speed in free driving conditions, they tend to drive at constant speed (PTV, 2011; Wiedemann, 1974), which is not observed in reality. Accordingly, additional efforts to adjust calibration parameters are needed.

Considering the driver behavior parameters of the traffic model, we excluded lane-change and simulation resolution. In the first case, we found that lane change parameters do not impact vehicle speeds. Concerning simulation resolution parameter, by default its value is ne step/(sim.s) in the VISSIM traffic model, which corresponds to a time step of $0.1 \mathrm{~s}$ for vehicle records data (instantaneous speed, acceleration/deceleration). Then, we used a value of 10 steps/(sim.s) in of(c) to fit the time resolution of traffic model and VSP emisston model input (a second-by-second basis).

In order to minimize the impacts of VISSIM limitations and to increase the reliability of VISSIM to predict on-road speed and acceleration profiles, we carried out some procedures
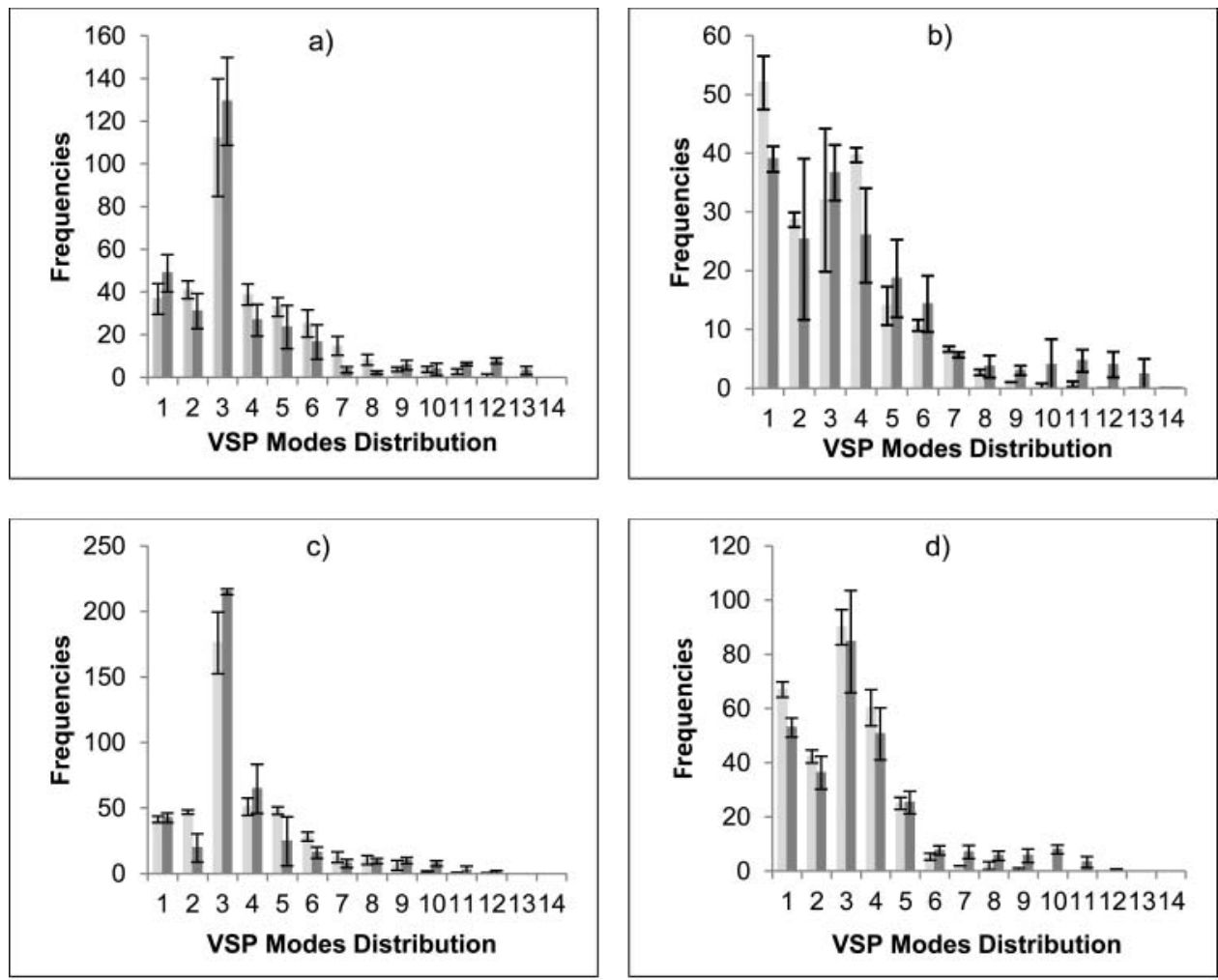

Observed

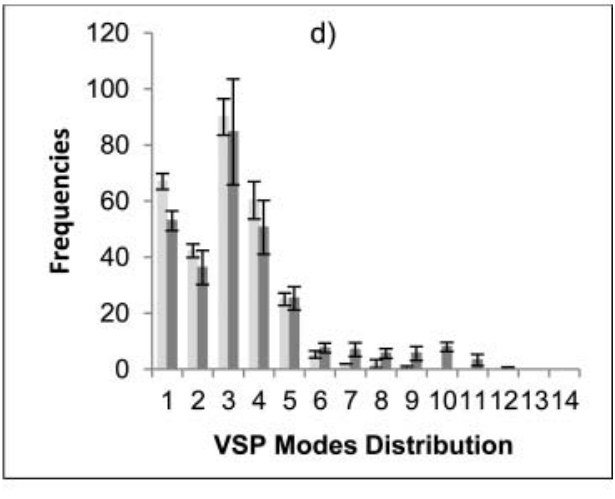

Simulated

Figure 4. Average and standard error VSP modes distribution for observed and simulated data: (a) route 1; (b) route 2; (c) route 3; (d) route 4. 
during the modeling of the baseline scenario. First, we used successive speed limits after or before a reduction area to 400 smooth as much as possible the acceleration and deceleration values. Second, the authors use speed limits in several sections of the arterial with a difference up to $3 \mathrm{~m} / \mathrm{s}$ (more or less) to avoid constant speeds.

By using the golden section method as a searching algorithm 405 for the optimal parameter value (Dowling et al., 2004) we selected 1.70 and 2.80 values for the additive and multiple part of safety distance, respectively, and selected a value of 1.25 meters for average standstill distance. Given the nature of this study, we decided to conduct 10 initial simulation runs (Hale, 1997) for each time-period scenario.

The comparison between simulated and observed hourly traffic flows for both morning and evening peak hours is provided in Table 4 for 10 initial random seed runs. The GEH statistic test for traffic flows for each counter was significantly less than 4 and RMSE rates did not exceed $5 \%$ in the two time periods. These validation results meet the hourly flow criteria in Dowling et al. (2004) and FHWA Travel Mode Improvement Program (2010).
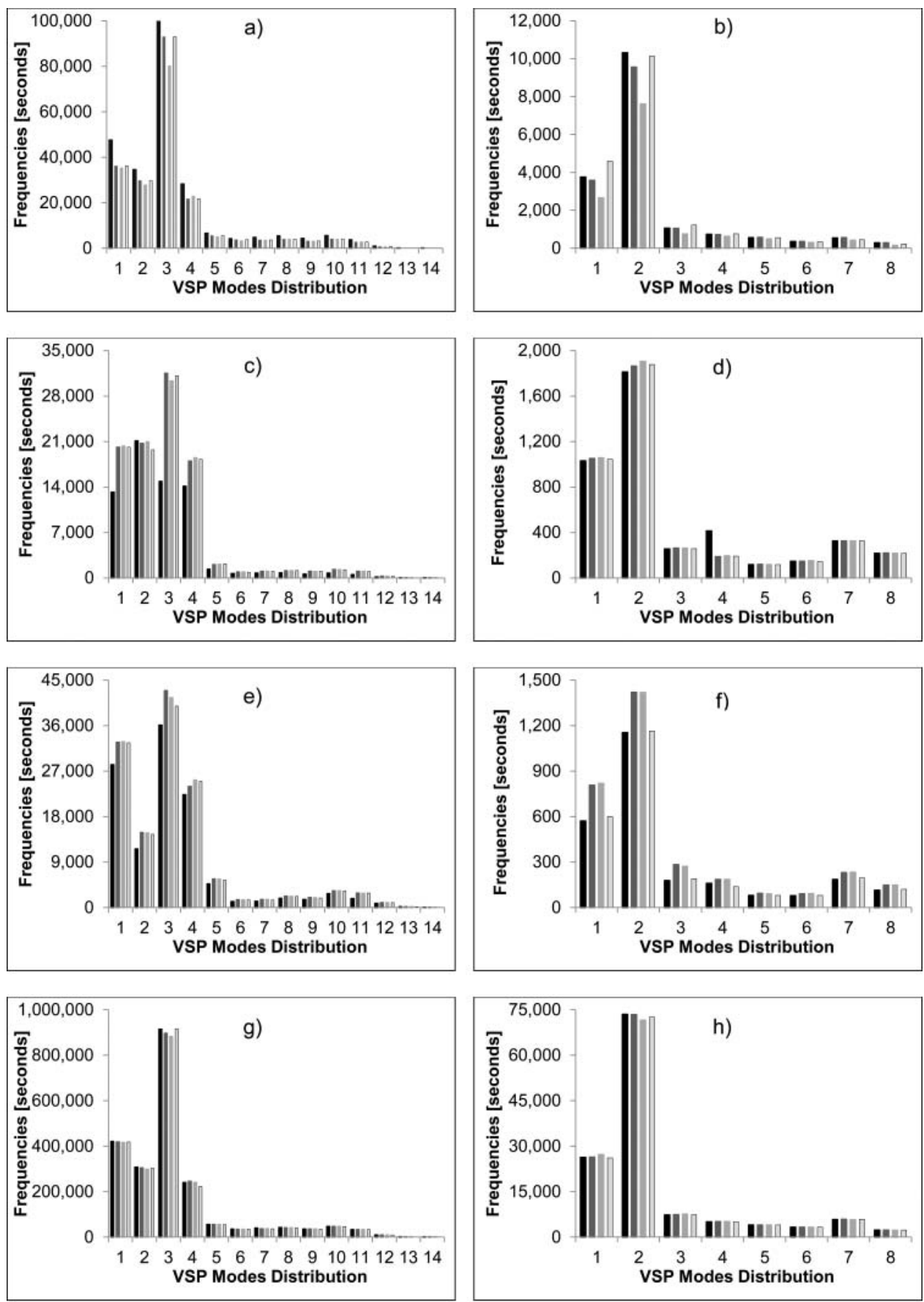

Figure 5. Average VSP modes distribution for each scenario during the morning peak hour (7-8 a.m.): (a) LDV in LA; (b) transit buses in LA; (c) LDV in AR1; (d) transit buses in AR1; (e) LDV in AR2; (f) transit buses in AR2; (g) LDV in ON; (h) transit buses in ON. 
Table 5 shows the comparison of travel times and speed profiles for the morning peak hour. For those parameters, we 420 achieved GEH values ranging from 0.1 to 0.5 , considering a number of floating car runs $\left(\mathrm{N}_{\mathrm{MIN}}\right)$ higher than recommended by Dowling et al. (2004). These results also indicated a good accuracy of traffic modeling process and they were much better than those obtained using default parameters (Table 3). Analy-

425 ses of the acceleration and speed estimation values in several points of selected routes resulted in the same conclusions as the above measures.

Figure 4 illustrates the VSP mode distributions of observed and simulated frequencies for each route performed. We

430 observed that VSP mode 3 is more prevalent on routes 1 (see Figure and 3 (see Figure 4.c). This can be explained by the higher 2 ber of traffic signals on both routes that led to more vehicle stops. The differences betwee e two VSP distributions arise in mode 3 , in which vehicles from simulation are

435 stopped for a longer time at traffic lights. In spite of having more prevalence on VSP modes higher than 5 (higher acceleration rates) and 1 and 2 (higher deceleration rates) on simulated data, we recorded a good fit between observed and simulated data sets of VSP modes distributions. The results of K-S statistic

440 test results at a $5 \%$ significance level ( $D$-value) with respect to the VSP distribution for routes 1 to 4 were, respectively, 0.086 $(p$-value $=0.15), 0.131(p$-value $=0.12), 0.068(p$-value $=0.28)$ and 0.100 ( $p$-value $=0.08)$ (Pearson, Pearson, \& Hartley, 1966). This means that two VSP modes distribution are drawn

445 from the same distribution. Concerning $\mathrm{CO}_{2}$ emissions, the relative difference ranges from $7 \%$ to $18 \%$. For each route performed, we did not find significant differences on means samples ( $p$-value $>0.05$ ). Analyses of the $\mathrm{CO}, \mathrm{HC}$, and $\mathrm{NO}_{\mathrm{X}}$ emissions per vehicle resulted in the same conclusions as the $450 \mathrm{CO}_{2}$ emissions.

\subsection{VSP modes distribution, emission rates, and traffic performance parameters}

In this section, we compare VSP modes distribution (LDV and transit buses), emissions $\left(\mathrm{CO}_{2}, \mathrm{CO}, \mathrm{NO}_{\mathrm{X}}\right.$, and $\left.\mathrm{HC}\right)$ and traffic performance parameters (number of vehicles, number of 455 vehicles stops, and delays) of the three traffic restriction scenarios in relation to the calibrated baseline scenario. The results are presented for LA area, for AR1 and AR2, and for the ON during the morning and evening peak hours and all vehicular emissions during the two time periods are considered.

\subsubsection{Morning peak hour}

Figure $5(\mathrm{a}-\mathrm{h})$ illustrates the average time spent in each VSP mode for each scenario and zone for the morning peak hour.

On average, LDV spent most of the time on VSP modes 1 and 3 while transit buses spent most of the time on VSP modes 1 and 2. All traffic restriction scenarios recorded lower frequency of VSP mode 3 (idling or low-speed situations) for LDV in the LA (see Figure 5-a). On that zone, Scenario 2 achieved the lowest frequency of VSP mode 3 in LDV and VSP mode 2 in transit buses (idling or low-speed situations). As 470 expected, all traffic restriction scenarios yielded higher freque cies of VSP bins on both alternative roads (AR1 and AR2) comparison to the line scenario (see Figure $5 \mathrm{c}-\mathrm{d}$ and Figure $5 \mathrm{e}-\mathrm{f}$ ). This was particularly noticeable on the VSP modes associated with high deceleration/acceleration rates and idling situations. Concerning the ON, we did not find significant differences on the frequency of VSP modes among scenarios uated (see Figure $5 \mathrm{~g}$-h). In particular, the bus-only lane also provided less idling and low speed situations (for both LDV and transit buses).

The emissions and traffic performance results on the morning peak hour are summarized in Table 6 for both baseline and traffic restriction scenarios.

Scenario 1 yielded a significant reduction in emissions, reaching similar $\mathrm{CO}_{2}, \mathrm{CO}$, and $\mathrm{HC}$ rates as scenario 2, with $29 \%, 30 \%$, and $27 \%$, respectively. Although the number of vehicles stops is reduced by $20 \%$, traffic delays are decreased by only $5 \%$. This is due to the reduction in the service road's capacity from 2 to 1 lane in that scenario. It was found that scenario 2 gave the best emissions scenario for the LA area, mainly in terms of $\mathrm{CO}_{2}$ and $\mathrm{CO}$ emissions with reductions of $30 \%$ and $32 \%$, respectively. The traffic performance measures also

Table 6. Variation of emissions and traffic performance parameters per location in relation to the baseline scenario, during the morning peak hour (7-8 a.m.).

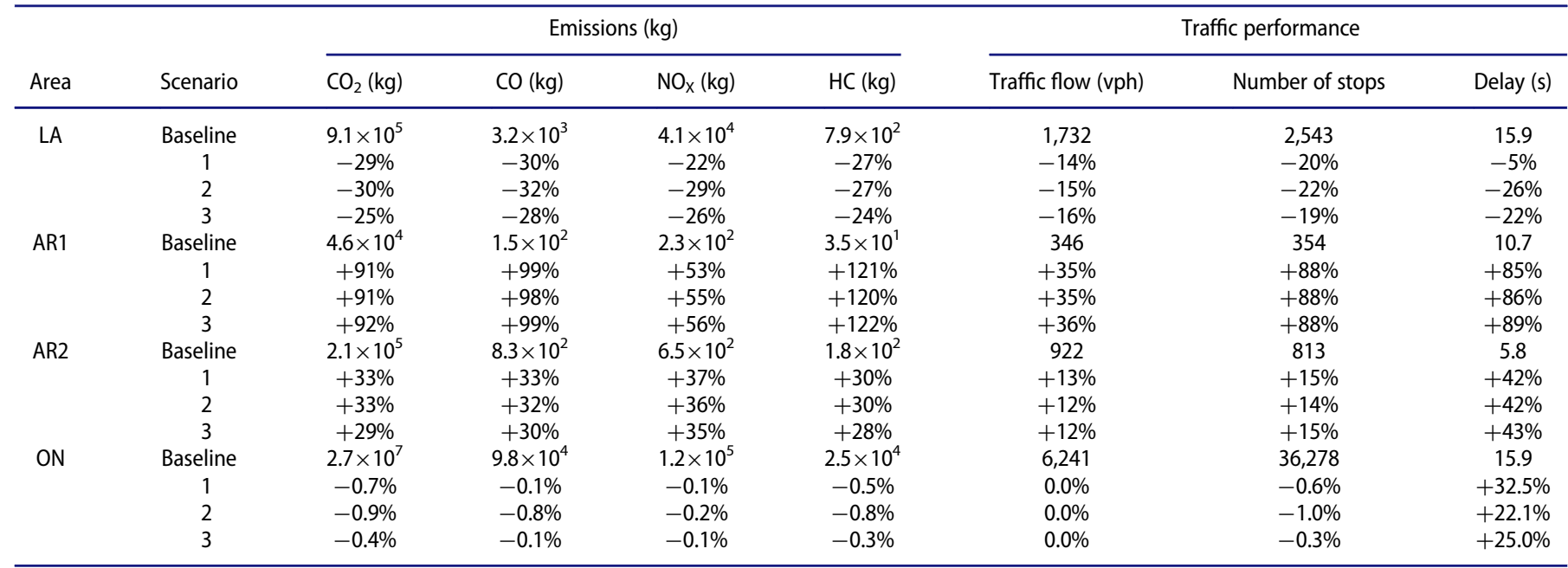


indicated scenario 2 as the better solution with the number of stops and delays reduced by more than $20 \%$. These findings confirm the values presented in Figure $5(\mathrm{a}-\mathrm{b})$ in which the bus-only lane scenario achieved the lowest frequency of VSP modes 3 and 2 for LDV and transit buses, respectively. The effects of closing central roads to traffic (Scena ${ }_{3}$ ) were smaller than the effects of the bus-only lan his was clear oth in terms of emissions and traffic performance measures.

As expected, AR1 showed an increase of vehicular emissions of more than $90 \%$ for $\mathrm{CO}_{2}, \mathrm{CO}$, and $\mathrm{HC}$ in all evaluation scenarios. Despite the increase in vehicles' volumes by $35 \%$, both vehicles' stops and delays increased by almost $90 \%$. In this case, AR1 is a single-lane road with several traffic lights on its boundaries that do not allow higher green times. It should also be mentioned that idle emissions on traffic restriction scenarios increased substantially $(+109 \%)$ compared to the baseline scenario.

Concerning AR2, the effect of traffic diversion most noticeable on $\mathrm{NO}_{\mathrm{X}}$ emissions with a substantial rise of almost $40 \%$, while the number of stops and delays also increased by
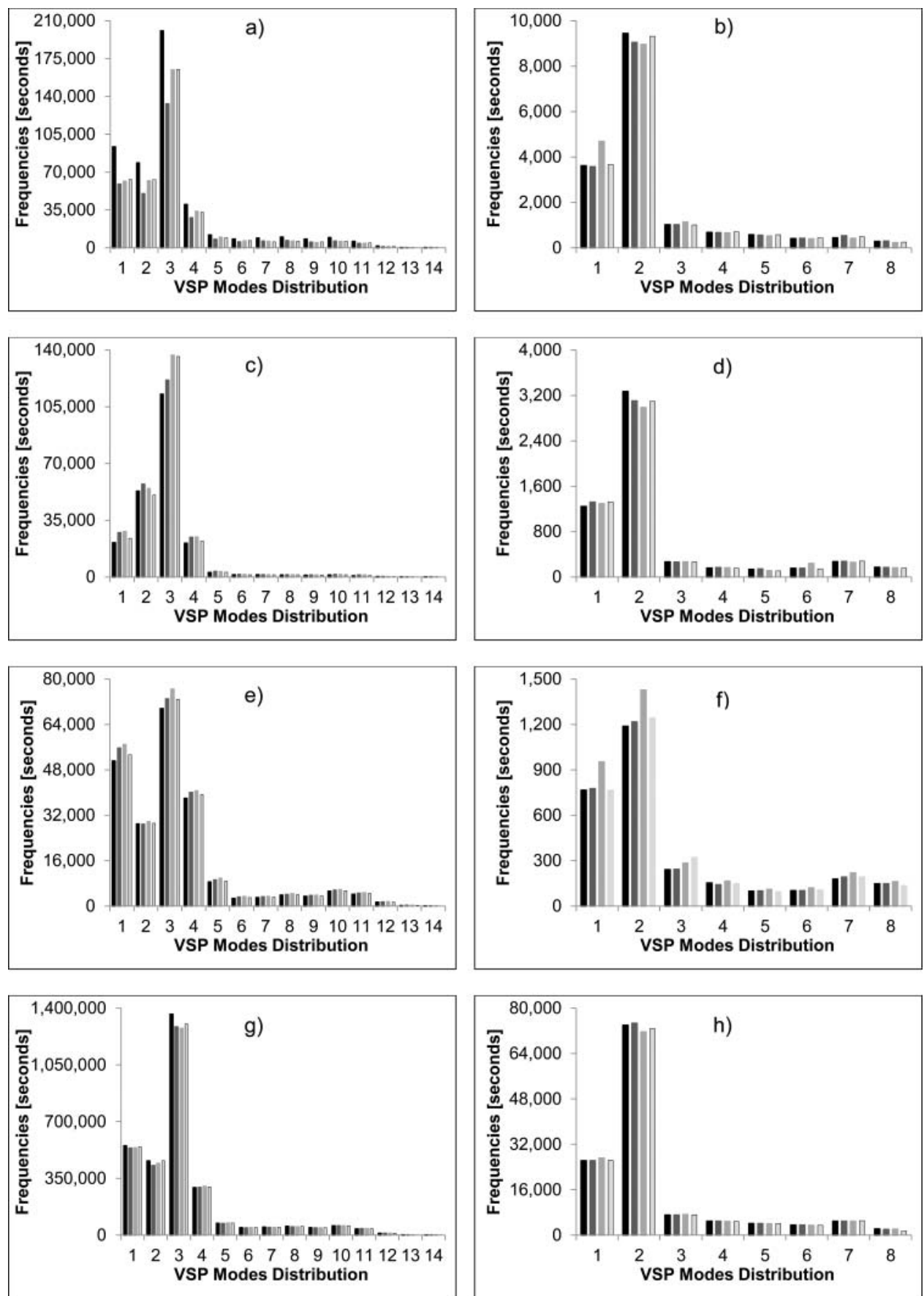

Baseline Scenario

Scenario 1

Scenario 2

Scenario 3

Figure 6. Average VSP modes distribution for each scenario during the evening peak hour (5-6 p.m.): (a) LDV in LA; (b) transit buses in LA; (c) LDV in AR1; (d) transit buses in AR1; (e) LDV in AR2; (f) transit buses in AR2; (g) LDV in ON; (h) transit buses in ON. 
$15 \%$ and $40 \%$, respectively. If we considered only idle emissions, the percentage increase in traffic restriction scenarios 515 exceeded $178 \%$ compared to the baseline scenario.

Considering the ON, the effects on emissions of traffic restriction measures were found to be rather small. VSP modes distributions were similar among scenarios (see Figure $5 \mathrm{~g}-\mathrm{h}$ ). Scenario 2 gave the highest $\mathrm{CO}_{2}$ emissions reduction by $1 \%$,

520 corresponding to almost 240 tons per hour. Furthermore, it also showed improvements in terms of $\mathrm{CO}$ and $\mathrm{HC}$ emissions savings of $0.8 \%$, while $\mathrm{NO}_{\mathrm{X}}$ slightly decreased by $0.2 \%$. For traffic measures, all scenarios yielded smaller reductions in vehicle stops, while delays increased in more than $20 \%$ of scenarios.

\section{3.2.2. Evening peak hour}

Figure 6 displays the VSP modes distribution for each scenario during the evening peak period in LA area, AR1, AR2, and ON. The frequency of VSP modes 1, 2, and 3 for LDV in all traffic restriction scenarios decreased considerably compared with the

530 baseline scenario (see Figure 6-a). Considering the alternative roads, we observed that traffic diversions from LA lead to an increase in the number of LDV stops (more VSP mode 3). Note that all vehicle types tend to have higher deceleration rates on these areas (see Figures 6-c and 6-e). For transit buses, as

535 illustrated in Figures 6-d and 6-f, we did not observed substantial differences on VSP modes distribution among scenarios. This can be explained by the minor contribution of this vehicle type $(<5 \%)$ on fleet composition. When analysis extended to the ON, the impact of traffic restriction measures became more

540 expressive in comparison to the morning peak hour. In particular, the dropping of one lane (scenario 1) achieved the lowest number of vehicle stops and low speed situations on both LDV and transit buses (see Figure $6 \mathrm{~g}-\mathrm{h}$ ).

Scenario 1 was the best mobility solution in terms of emis-

545 sions. It had an average $\mathrm{CO}_{2}, \mathrm{CO}$, and $\mathrm{HC}$ emissions reduction of about $50 \%$ and recorded the smallest number of vehicle stops, with 33\% (see Table 7). This is explained by its good environmental and traffic performance on both time periods mainly in the evening peak hour even if considering the higher 550 traffic flow on the northbound lane during that period. Despite its environmental benefits improvement, this scenario is shown to be less effective in terms of delays compared to others traffic restriction scenarios as a result of the high ratio between traffic flows and capacity on the service roads that are restricted to one lane. Scenarios 2 and 3 yielded similar emission reductions on the LA area (see Table 7), with the exception of HC pollutant. Specifically, the bus-only lane implementation allowed hydrocarbons to be reduced by $47 \%$.

The average increase in emissions ranged from $27 \%$ to $30 \%$ between scenarios 1 and 3 for a traffic flow increase between $10 \%$ and $11 \%$. Particularly relevant was the increase in stops (see Figure $6 c-d$ ), reaching $76 \%$ for scenario 2 . From these results, it was clear that vehicles avoided the use of AR1 as a path for their trips, in spite of the lower capacity imposed on LA.

AR2 also yielded increased emissions in all restriction scenarios, namely, $25 \%$ for $\mathrm{NO}_{\mathrm{X}}$ and around $20 \%$ for $\mathrm{CO}_{2}, \mathrm{CO}$, and $\mathrm{HC}$, in both scenarios 2 and 3 . The changes in traffic performance parameters were less dramatic. In this case, the number of stops increased $12 \%$, while delay increased by $16 \%$ and $18 \%$ for scenarios 1 and 2, respectively. Although idle emissions produced on traffic restriction scenarios sharply increased $15 \%$ and $6 \%$ in AR1 and AR2, respectively, in comparison to the baseline scenario, they alone contributed with $40 \%$ and $17 \%$ of the total emissions.

Considering the $\mathrm{ON}$, the impact of traffic restriction scenarios was more significant in comparison to the morning peak hour conditions. These results were in accordance with VSP modes distribution presented previously for LDV (see Figure 6g). Scenario 1 provided the lowest vehicular emissions for all pollutants analyzed. In this case, we recorded emissions reductions of $4.1 \%, 3.2 \%, 7.6 \%$, and $4.1 \%$ for $\mathrm{CO}_{2}, \mathrm{CO}, \mathrm{NO}_{\mathrm{X}}$, and $\mathrm{HC}$, respectively. Moreover, scenario 1 also yielded fewer stops, with a reduction of $2.4 \%$. As suspected, the traffic diversion had effects on delays in all restriction scenarios with increases close to $20 \%$ due to some traffic congestion on alternative roads. Doubtless, these values point out the potential negative impacts of the measures evaluated here in some stretches of the selected case study area.

Table 7. Variation of emissions and traffic performance parameters per location in relation to the baseline scenario, during the evening-peak hour (5-6 p.m.).

\begin{tabular}{|c|c|c|c|c|c|c|c|c|}
\hline \multirow[b]{2}{*}{ Area } & \multirow[b]{2}{*}{ Scenario } & \multicolumn{4}{|c|}{ Emissions (kg) } & \multicolumn{3}{|c|}{ Traffic performance } \\
\hline & & $\mathrm{CO}_{2}(\mathrm{~kg})$ & $\mathrm{CO}(\mathrm{kg})$ & $\mathrm{NO}_{\mathrm{X}}(\mathrm{kg})$ & $\mathrm{HC}(\mathrm{kg})$ & Traffic flow (vph) & Number of stops & Delay (s) \\
\hline \multirow[t]{4}{*}{$\mathrm{LA}$} & Baseline & $2.2 \times 10^{6}$ & $7.6 \times 10^{3}$ & $7.4 \times 10^{3}$ & $2.3 \times 10^{3}$ & 2,464 & 5,473 & 35.7 \\
\hline & 1 & $-48 \%$ & $-49 \%$ & $-38 \%$ & $-51 \%$ & $-24 \%$ & $-33 \%$ & $-24 \%$ \\
\hline & 2 & $-44 \%$ & $-46 \%$ & $-34 \%$ & $-47 \%$ & $-27 \%$ & $-28 \%$ & $-31 \%$ \\
\hline & 3 & $-44 \%$ & $-45 \%$ & $-34 \%$ & $-44 \%$ & $-26 \%$ & $-28 \%$ & $-29 \%$ \\
\hline \multirow[t]{4}{*}{ AR1 } & Baseline & $1.8 \times 10^{5}$ & $5.1 \times 10^{2}$ & $5.5 \times 10^{2}$ & $2.4 \times 10^{2}$ & 563 & 1211 & 94.6 \\
\hline & 1 & $+23 \%$ & $+28 \%$ & $+22 \%$ & $+34 \%$ & $+10 \%$ & $+74 \%$ & $+33 \%$ \\
\hline & 2 & $+27 \%$ & $+29 \%$ & $+24 \%$ & $+36 \%$ & $+11 \%$ & $+76 \%$ & $+34 \%$ \\
\hline & 3 & $+31 \%$ & $+30 \%$ & $+25 \%$ & $+35 \%$ & $+11 \%$ & $+75 \%$ & $+34 \%$ \\
\hline \multirow[t]{4}{*}{ AR2 } & Baseline & $6.1 \times 10^{5}$ & $2.4 \times 10^{3}$ & $1.7 \times 10^{3}$ & $5.5 \times 10^{2}$ & 1,483 & 1,581 & 9.9 \\
\hline & 1 & $+17 \%$ & $+18 \%$ & $+16 \%$ & $+16 \%$ & $+11 \%$ & $+12 \%$ & $+16 \%$ \\
\hline & 2 & $+22 \%$ & $+22 \%$ & $+25 \%$ & $+20 \%$ & $+12 \%$ & $+12 \%$ & $+18 \%$ \\
\hline & 3 & $+21 \%$ & $+21 \%$ & $+25 \%$ & $+19 \%$ & $+12 \%$ & $+12 \%$ & $+18 \%$ \\
\hline \multirow[t]{4}{*}{ ON } & Baseline & $4.1 \times 10^{7}$ & $1.4 \times 10^{5}$ & $1.5 \times 10^{5}$ & $4.1 \times 10^{4}$ & 7,245 & 63,081 & 87.3 \\
\hline & 1 & $-4.0 \%$ & $-3.2 \%$ & $-7.6 \%$ & $-4.1 \%$ & $+0.2 \%$ & $-2.4 \%$ & $16.3 \%$ \\
\hline & 2 & $-2.6 \%$ & $-2.2 \%$ & $-3.5 \%$ & $-3.9 \%$ & $+0.1 \%$ & $-2.3 \%$ & $17.6 \%$ \\
\hline & 3 & $-2.2 \%$ & $-1.2 \%$ & $-3.5 \%$ & $-3.4 \%$ & $+0.1 \%$ & $-1.3 \%$ & $18.5 \%$ \\
\hline
\end{tabular}

Notes. LA: Liberdade Avenue; AR1: Alternative Road 1; AR2: Alternative Road 2; ON: Overall Network. 

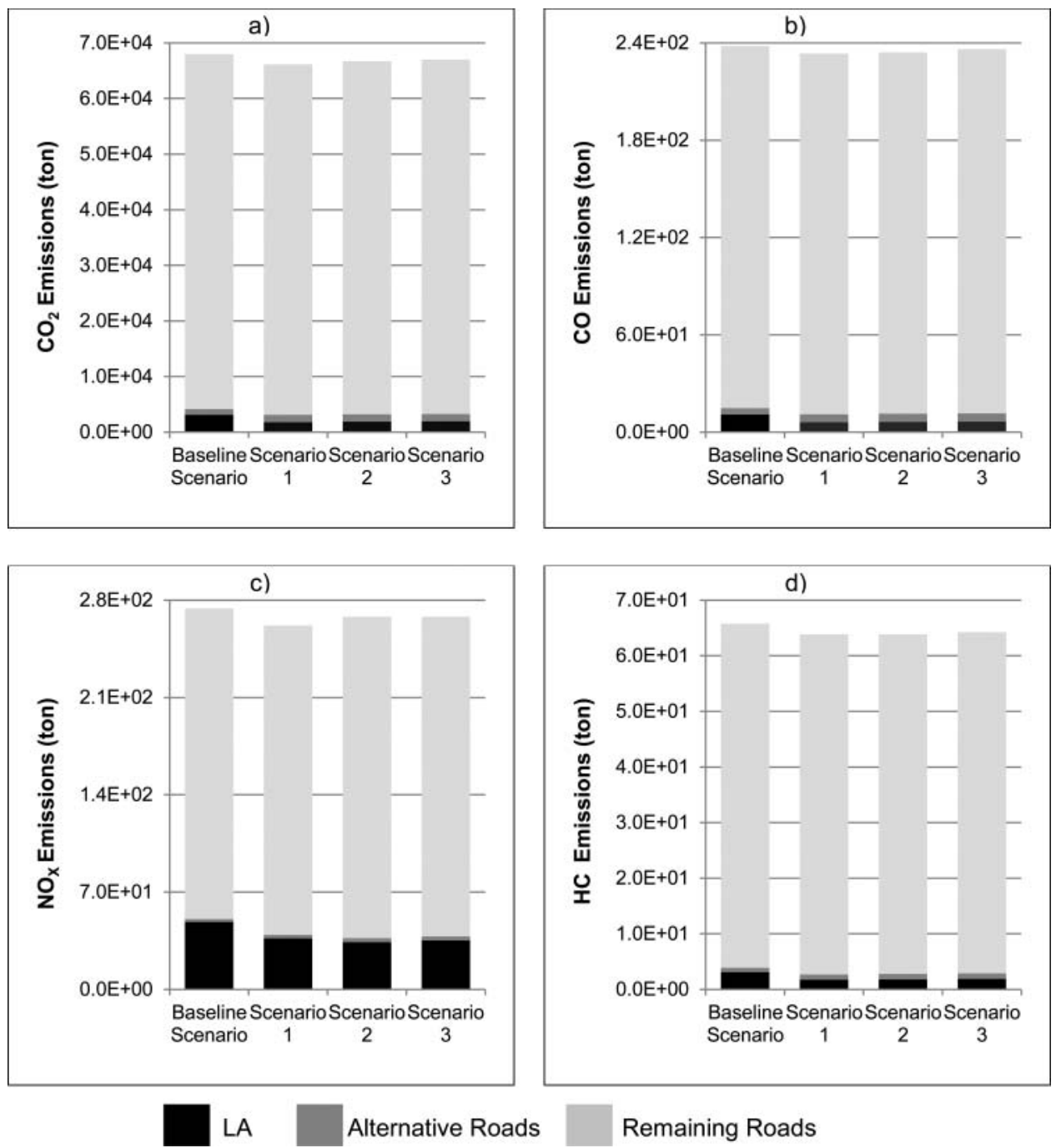

Figure 7. Total of emissions (ton) of the two time perid rs scenario: (a) $\mathrm{CO}_{2}$ ( (b) $\mathrm{CO}_{\text {; }}$ (c) $\mathrm{NO}_{\mathrm{x}}$; (d) $\mathrm{HC}$.

Figure 7 plots the total emissions produced by two time periods for the baseline and all traffic restriction scenarios. From a $\mathrm{CO}_{2}$ criterion, scenario 1 gave the best emissions scenario for the overall network, with about $4 \%$ reductions in comparison to

595 scenarios 2 and 3. This corresponds to more than 2,000 tons of $\mathrm{CO}_{2}$ emitted during the two time periods. Analyses of the local pollutants associated with traffic resulted in the same conclusions as the $\mathrm{CO}_{2}$ emissions. The results presented in Figure 7 also show that the emissions contribution of the LA and AR1

600 and AR2 was rather small on the ON. This was particularly visible on $\mathrm{CO}_{2}$, whose emissions contribution from the three above areas did not exceed $5 \%$ in all traffic restriction scenarios.

\section{Conclusions}

This paper provides a methodological framework for the assess-

sions and traffic performance parameters using a microscopic traffic simulation model combined with an emission model. The case study considered was an urban arterial with two central roads. A limited number of alternative paths were also 610 taken into account.
The main conclusions of this research are:

- For the morning peak hour, the highest average emissions reduction predicted on LA are associated with bus-only lane seal at $30 \%$;

- Dropping one through lane is shown to be the best mobility scenario for LA during the evening peak hour during which average emissions reductions reached $47 \%$;

- Traffic diversions contributed to additional congestion on alternative roads and increased emissions in those areas, namely for $\mathrm{CO}_{2}, \mathrm{CO}$, and $\mathrm{HC}$ emissions, with increases of 620 more than $90 \%$ above the baseline scenario;

- Considering the $\mathrm{ON}$ and summing the emissions contribution of the morning and evening peak periods, the drop of one lane is the best mobility solution.

Therefore, it can be argued that the findings of this paper confirm some of previous studies. Note that the methodology can be generalized to other urban arterials with similar traffic flows. Moreover, this methodology can be tailored to assess other traffic restriction policies in real-world case studies that have already been implemented, and whose impacts were not thoroughly evaluated. Because of the importance of more before and after studies to address their environmental and traffic performance impacts on real-world case studies, the 
methodology presented in this research is also useful for similar

635 analysis. Nevertheless, there are some limitations that must be highlighted. One of them is the exclusion of traffic incidents (such as collisions or work zones) on the comparison among different traffic measures. Another limitation is the lack of dynamic route selection that takes into account an environ-

640 mental criterion. Currently, traffic models use distance, time, and cost functions to assign vehicle routes across the network. A traffic assignment procedure taking into account environmental criteria could optimize the effects of traffic restriction measures on the overall network (Bandeira et al., 2013). The

645 third limitation concerns the exclusion of the Heavy Duty Vehicles. It must be emphasized that in the study domain, this class represented less than $1 \%$ of road traffic. However, in the cases with a higher percentage, it must be considered that the driving patterns of this vehicle type are different from Light

650 Duty Vehicles, which could have a significant effect on emissions and traffic performance.

\section{Acknowledgments}

The authors acknowledge the Municipality of Lisbon and Dr. Gonçalo Gonçalves (Mechanical Engineering Institute of Instituto Superior

655 Técnico), for their cooperation in the project. This work was partially funded by FEDER Funds through the Operational Program "Factores de Competividade-COMPETE" and by National Funds through FCTFundação para a Ciência e Tecnologia within the projects PTDC/SENTRA/113499/2009 and PTDC/SEN-TRA/115117/2009, and by the Strate-

660 gic Project PEst-C/EME/UI0481/2011. M.C. Coelho acknowledges the support of FLAD-Luso American Foundation (Project 91-03/2010, within the program FLAD/NSF- "Project USA: Networks and Partnerships for Research"). The collaboration between Dr. Coelho and Dr. Rouphail was under the auspices of the Luso-American Transportation Impacts Study 665 Group (LATIS-G)

\section{References}

Acap. (2012). Automobile industry statistics 2010 edition. Acap (Automobile Association Of Portugal).

Aziz, H. M. A., \& Ukkusuri, S. (2011, January). Environmental objectives within a dynamic traffic assignment framework: A step towards green transportation. Paper presented at the 90th Transportation Research Board Meeting, Washington, DC.

Bandeira, J. M., Coelho, M. C., Sá, M. E., Tavares, R., \& Borrego, C. (2011). Impact of land use on urban mobility patterns, emissions and air qual-

675 ity in a portuguese medium-sized city. Science of the Total Environment, 409(6), 1154-1163. Retrieved from http://www.sciencedirect. com/science/article/pii/S0048969710013112

Bandeira, J. M., Pereira, S. R., Fontes, T., Fernandes, P., Khattak, A. J., \& Coelho, M.C. (2013). An "eco-traffic" assignment tool. Paper presented at the 16th Euro Working Group on Transportation, Porto, Portugal.

Barros, N., Fontes, T., Silva, M. P., \& Manso, M. C. (2013). How wide should be the adjacent area to an urban motorway to prevent potential health impacts from traffic emissions? Transportation Research Part A: Policy and Practice, 50, 113-128. Retrieved from http://www.sciencedir ect.com/science/article/pii/S0965856413000281

Castro, J. T., \& Delos Reyes, M. R. (2010). Estimating traffic and emissions for various scenarios of freight vehicle restrictions in metro manila. Asian Transport Studies, 1, 4-17.

Chen, K., \& Yu, L. (2007). Microscopic traffic-emission simulation and 690 case study for evaluation of traffic control strategies. Journal of Transportation Systems Engineering and Information Technology, 7(1), 9399. Retrieved from http://www.sciencedirect.com/science/article/pii/ S1570667207600117
Coelho, M. C., Farias, T. L., \& Rouphail, N. M. (2009). A numerical tool for estimating pollutant emissions and vehicles performance in traffic interruptions on urban corridors. International Journal of Sustainable Transportation, 3(4), 246-262. Retrieved from: http://dx.doi.org/ $10.1080 / 15568310802175641$

Coelho, M. C., Frey, H. C., Rouphail, N. M., Zhai, H., \& Pelkmans, L. (2009). Assessing methods for comparing emissions from gasoline and diesel light-duty vehicles based on microscale measurements. Transportation Research Part D: Transport and Environment, 14(2), 91-99. Retrieved from http://www.sciencedirect.com/science/article/pii/ S1361920908001429

Dowling, R., Skabadonis, A., \& Alexiadis, V. (2004). Traffic analysis toolbox volume iii: guidelines for applying traffic microsimulation software. Washington, DC: Federal Highway Administration, U.S. Department of Transportation.

Eea (European Environment Agency). (2013). Greenhouse gas emissions by sector. Retrieved 13 October 2013 From http://epp.eurostat.ec. europa.eu/tgm/refreshTableAction.do?

tab $=$ table $\&$ plugin $=1 \&$ pcode $=$ tsdcc $210 \&$ language $=$ en

Everitt, B. S., \& Hothorn, T. (2006). A handbook of statistical analyses using $R$. Taylor \& Francis.

Fellendorf, M., \& Vortisch, P. (2010). Microscopic traffic flow simulator vissim. In J. Barceló (Ed.), Fundamentals of Traffic Simulation (pp. 6393). New York, NY: Springer.

FHWA Travel Mode Improvement Program. (2010). Travel model validation and reasonableness checking manual (2nd ed.). Washington, DC: Federal Highway Administration, U.S. Department of Transportation.

Fontes, T., Fernandes, P., Rodrigues, H., Bandeira, J., Pereira, S., Khattak, A. J., \& Coelho, M. C. (2013). Are ecolanes a sustainable option to reduce emissions in a medium-sized European city? Transportation Research Part A: Policy and Practice, in press.

Frey, H. C., Rouphail, N. M., Zhai, H., Farias, T. L., \& Gonçalves, G. A. (2007). Comparing real-world fuel consumption for diesel- and hydrogen-fueled transit buses and implication for emissions. Transportation Research Part D: Transport and Environment, 12(4), 281-291. Available from http://www.sciencedirect.com/science/article/pii/ S1361920907000272.

Frey, H. C., Zhang, K., \& Rouphail, N. M. (2008). Fuel use and emissions comparisons for alternative routes, time of day, road grade, and vehicles based on in-use measurements. Environmental Science \& Technology, 42(7), 2483-2489 Retrieved from http://dx.doi.org/10.1021/ Es702493v

Hale, D. (1997). How many netsim runs are enough? McTrans, 11(3), 1-9. Int Panis, L., Beckx, C., Broekx, S., De Vlieger, I., Schrooten, L., Degraeuwe, B., \& Pelkmans, L. (2011). PM, NOx and $\mathrm{CO}_{2}$ emission reductions from speed management policies in Europe. Transport Policy, 18(1), 32-37. Retrieved from http://www.sciencedirect.com/science/article/ pii/S0967070 $\times 10000739$

Invernizzi, G., Ruprecht, A., Mazza, R., De Marco, C., Močnik, G., Sioutas, C., \& Westerdahl, D. (2011). Measurement of black carbon concentration as an indicator of air quality benefits of traffic restriction policies within the ecopass zone in Milan, Italy. Atmospheric Environment, 45 (21), 3522-3527. Retrieved from http://www.sciencedirect.com/sci ence/article/pii/S1352231011003645

Kolak, O. I., Feyzioglu, O., Birbil, S. I., Noyan, N., \& Yalcindag, S. (2013). Using emission functions in modeling environmentally sustainable traffic assignment policies. Journal of Industrial and Management Optimization, 9(2). Retrieved from http://www.aimsciences.org/journals/dis playArticlesnew.jsp?paperID $=8285$

Lee, G., You, S., Ritchie, S. G., Saphores, J.-D., Jayakrishnan, R., \& Ogunseitan, O. (2012). Assessing air quality and health benefits of the Clean Truck Program in the Alameda corridor, CA. Transportation Research Part A: Policy and Practice, 46(8), 1177-1193. Retrieved from http:// www.sciencedirect.com/science/article/pii/S0965856412000808

Madireddy, M., De Coensel, B., Can, A., Degraeuwe, B., Beusen, B., De Vlieger, I., \& Botteldooren, D. (2011). Assessment of the impact of speed limit reduction and traffic signal coordination on vehicle emissions using an integrated approach. Transportation Research Part D: Transport and Environment, 16(7), 504-508. Retrieved from http:// www.sciencedirect.com/science/article/pii/S1361920911000812 
Mahmod, M., Van Arem, B., Pueboobpaphan, R., \& Igamberdiev, M. (2010). Modeling reduced traffic emissions in urban areas: The impact of demand control, banning heavy duty vehicles, speed restriction and adaptive cruise control. Paper presented at the 89th TRB Annual Meeting, Washington, DC.

Nesamani, K. S., Chu, L., \& Recker, W. (2010). Policy implications of incorporating hybrid vehicles into high-occupancy vehicle lanes. Journal of Transportation Systems Engineering and Information Technology, 10(2), 30-41. Retrieved from http://www.sciencedirect.com/science/arti cle/pii/S1570667209600313

Pearson, E. S., Pearson, K., \& Hartley, H. O. (1966). Biometrika tables for statisticians. Published for the Biometrika Trustees at the University Press.

PTV. (2011). Vissim 5.30-05 user manual. Karlsruhe, Germany: Planung Transport Verkehr AG.

Qu, T., Rillet, L. R., Zhang, K., \& Zietsman, J. (2003). Estimating the impact of freeway speed limits on automobile emissions. Paper presented at the $82 \mathrm{nd}$ TRB Annual Meeting, Washington, DC.

Stevanovic, A., Stevanovic, J., Zhang, K., \& Batterman, S., 2009. Optimizing traffic control to reduce fuel consumption and vehicular emissions: AN integrated approach of VISSIM, CMEM, and VISGAOST. Transportation Research Record, 2128, 105-113.

Torné, J., Rosas, D., \& Soriguera, F. (2011). Evaluation of speed limit management on c-32 highway access to Barcelona. Paper presented at the 90th TRB Annual Meeting, Washington, DC.

U.S. Epa. (2002). Methodology for developing modal emission rates for EPA's multi-scale motor vehicle \& equipment emission system (Publication EPA420-R-02-027). Washington, DC: Author.

Wiedemann, R. (1974). Simulation des straßenverkehrsflusses (Schriftenreihe des Instituts für Verkehrswesen der Universität Karlsruhe, Heft 8). Karlsruhe, Germany: Institute Of Transportation, University Of Karlsruhe.

Zhai, H., Frey, H. C., \& Rouphail, N. M. (2008). A vehicle-specific power approach to speed- and facility-specific emissions estimates for diesel transit buses. Environmental Science \& Technology, 42(21), 7985-7991. Retrieved from http://dx.doi.org/10.1021/Es800208d

Zhang, Y., Chen, X., Zhang, X., Song, G., \& Yu, L. (2009). Assessing effect of traffic signal control strategies on vehicle emissions. Journal of Transportation Systems Engineering and Information Technology, 9(1), 150-155. 